\title{
New theoretical perspectives on technology adoption
}

\author{
Robert J. Kauffman • \\ Angsana A. Techatassanasoontorn
}

Published online: 14 December 2010

(C) Springer Science+Business Media, LLC 2010

There is a growing recognition that the adoption and extensive diffusion of new ITs and technological innovations that support social networking are critical to support the related growth of our information-rich society in a way that benefits people and organizations. Similarly important is how the emergence of new technological innovations changes the way that organizations survive and thrive in the highly competitive environment of the global economy. Another frontier for impact of new technologies is at the country level for sustainable social and economic development. Some examples include the emergence of mobile and Internet-based telephony, open software systems, infrastructure and application support for digital social networks, digital entertainment services on the Internet, and more intelligent hardware-based data storage systems. Their incorporation into innovative products and services has had dramatic benefits at all these different levels.

The research literature on the adoption and diffusion of new technologies and innovations is voluminous and has identified numerous relevant factors associated with adoption and diffusion across multiple levels of analysis. For instance, the popular technology acceptance model has offered a parsimonious theory to explain individual-level adoption and use of new innovations. Similarly, research at the organizational and interorganizational levels has been able to explain the impetus for the adoption of

R. J. Kauffman $(\bowtie)$

W. P. Carey School of Business, Arizona State University, Tempe, AZ 85287, USA

e-mail: rkauffman@asu.edu

A. A. Techatassanasoontorn

College of Information Sciences and Technology, Pennsylvania

State University, University Park, PA 16802, USA

e-mail: angsanat@ist.psu.edu technological innovations based on multiple relevant perspectives. They include theories of: organizational readiness; innovation ownership and co-investment considerations; the appropriation of value from contemporary versus future-oriented value flows associated with technology adoption; and the acceleration and deceleration of firm-level technology adoption in competitive markets.

There still are many opportunities for theory development in the adoption and diffusion of new technological innovations though. Although much of the research in the Information Systems discipline up to the present has emphasized individual adoption of new technologies, a broader umbrella of research is appropriate that offers rich theory about technology adoption by accounting for the relevant technological, institutional, national and historical contexts. It is also appropriate to develop research on technology innovation and adoption that moves beyond the dominant paradigm of establishing the relationships between the independent variables of innovator profiles, and the dependent variables of innovation quantity and quality. Some of the promising opportunities for theory development involve such perspectives as contagion effects, management fashion, innovation mindfulness, technology ecosystems and innovation life cycles, innovation configurations, the evolution and impacts of standards organizations, and quality-led innovation and technology adoption.

Our motivation for this special issue-actually the first of several for Information Technology and Managementwas to engage researchers from the international academic and business communities who are thought leaders and practice innovators to work collaboratively on the development of new theoretical perspectives and methods advances related to research on technology adoption. Through this effort, we were fortunate to have attracted 
numerous submissions from authors who expressed an interest in the development and extension of theories of technology adoption that draw upon individual and organizational behavior, psychology and sociology, and strategy and economics. In this special issue, we have selected for publication three new works by authors who explore technology adoption issues in the following contexts: technologies that have high expectations and unusual hype associated with them in the public's mind; corporate Web sites that support online recruiting of employees; and mechanism design and consumer behavior and usage of Internet-based group-buying auctions. These settings for research have unique individual, business process, organizational, economy and other contextual reasons that have prompted the authors to develop new or extend existing theoretical perspectives for understanding how technology adoption works.

The special issue opens with a piece by Jonas Hedman and Gregory Gimpel, entitled "The Adoption of Hyped Technologies: A Qualitative Study." Their work employs a new and unique theoretical perspective for technology adoption research: the theory of consumption values. The theory posits that there are five different kinds of value that influence consumer behavior, and by the authors' extension, their technology adoption behavior also. They include functional, social, epistemic, emotional and conditional value. Functional value and social value should be familiar for most readers who have followed the development of the literature on technology adoption, since these dimensions are present in other works. The authors characterize epistemic value as stemming from an adopter's curiosity, desire to learn, or urge to experience something new related to some technology of interest. Also, conditional value, the authors propose, acts as a modifier of other kinds of value that occur conditionally, when different situational aspects arise. For example, a telephone exhibits unique functional value when there is some condition that arises, like a family emergency at home (e.g., a grandparent with symptoms of a heart attack), while a mobile phone may be especially useful when a user is traveling (e.g., if there has been an automobile accident, and someone needs to call emergency medical services). Finally, emotional value may arise when an adopter considers the aesthetics of a given technology: the "coolness" of the design of the early 2000 s cell phones that embedded tiny digital cameras, or the social status that went along with the early adoption of an Apple iPad in 2010.

Hedman and Gimpel identified these aspects of their theory as potential explanatory reasons for why hyped technologies often are adopted in the bandwagon fashion that we observe. They focused on intrinsic drivers and extrinsic drivers for adoption, and used a blend of qualitative methods involving groups and individual interviews to show that emotional value, epistemic value and social value seem to be the most influential of the five value categories. As a knowledgeable observer might guess, functional value had little explanatory power in the context of hyped technology adoption. The authors' contribution to the special issue enhances our understanding of relevant theory for how the adoption of hyped technologies works.

The second article of the special issue addresses "The Importance of Trusting Beliefs Linked to the Corporate Website for Diffusion of Recruiting-Related Online Innovations." The authors, Maria Bermúdez-Edo, Nuria Hurtado-Torres and J. Alberto Aragon-Correa, explore the adoption of technological innovations in online recruiting from the perspective of the theory of reasoned action. In particular, the authors assert that problems with trust on the part of potential employees may make online recruiting less than ideal from the recruiter's point of view. So even though the use of online tools for finding new employees tends to increase the geographic range of a firm's recruiting activities, it is still difficult for potential employees to accept advances from small, less well-known companies that are not members of a mainstream industry. The digital playing field isn't quite as level as companies hope it can be.

Using experimental methods, the authors studied the reactions of subjects to fictitious online recruiting efforts for offers of a position in consulting in terms of three key hypotheses: a firm integrity hypothesis, a firm benevolence hypothesis, and a firm ability hypothesis. The authors' primary results suggest that the perceptions that users obtain about a firm through its Web site are important. Prospective employees need to be supported in the development of beliefs in the firm's integrity in its business dealings and its benevolence with respect to its hiring and employment practices. This, the authors suggest, can be accomplished on the firm's Web site through a variety of means, including additional details about the business, and testimonials from current employees about the nature of employment at the firm. They argue that, for recruiting purposes at least, a firm's Web site should not be presented as an emotionally flat environment, but instead, as one that supports the discovery of distinguishing information and provides a capable platform for rich interactions with potential employees. From the point of view of employment recruiting, the role of the firm's Web site should be to create the basis for a willingness to work on the part of employment candidates who are recruited through this means-something that has proven to be challenging in corporate recruiting to date, in spite of the great "reach" that the Internet provides.

The final article of this special issue is entitled "Consumer Adoption of Group-Buying Auctions: An Experimental Study," by Robert J. Kauffman, Hsiangchu Lai and 
Huang-chi Lin. Of late, hybrid forms of online groupbuying have staged a resurgence in markets and among consumers who were once much more skeptical about what benefits were offered. The failures in group-buying Web sites of the early to mid-2000s are well known, and included investors such as Paul Allen, one of Microsoft's founders. These group-buying firms included Mercata, Mobshop, C-Tribe, Online Choice, Etrana, and LetsBuyIt, among others. These first-generation online group-buying firms have now been supplanted by a new generation of players, with more effective business models and greatly enhanced technological approaches-although they do not exploit the same kinds of group participation and buyer power aggregation as before. They use them to identify and subscribe people to create buying pools of sufficient size to increase the likelihood that they will succeed as start-ups, but the emphasis is more on social network-driven buying than it is on one-time bid-in-auction style mechanisms. These new group-buying firms include LivingSocial, Yipit, Groupon, Tippr, and eSwarm, and quite a few more around the world. Among these, Groupon was recently the target of an unsuccessful US\$6 billion acquisition bid from Google. This reflects Groupon's capacity to generate high revenues in support of social network-based coupon sales for consumers to purchase some goods or services at a later date. The latter is social couponing, an emergent mechanism design representing the move in the marketplace to "Group-Buying 2.0" business models.

In the present research, the authors explore the performance of a mechanism design for group-buying auction intermediation that involves the services of a group-buying auction initiator. The authors note that this can be an established intermediary, a company that gets involved through an intermediary, or an individual person who gets involved through an intermediary. Similar to the published research on biased markets and buyer and seller-side ownership structures of Yoo, Choudhary and Mukhopadhyay (2007) in Management Science, the authors posit that participant-owned and participant-operated auction mechanisms can be of high value for everyone involved. The research of the present authors implemented an experimental study using an online group-buying auction testbed. They studied the bidding behavior of participants who experienced uncertainty about the auction initiator, the final auction price for the trade item being transacted, and whether the auction would result in completed economic exchange. They did this for relatively small lot sales of the products offered by small enterprises. The authors' theory development centers on perceived psychological and financial risks, as well as trust in the initiator, as a means of gauging how well the mechanism design works. Their results suggest that textual comments about sellers and the density of current bids mitigate concerns about uncertainty.
It was more difficult for the auction initiator to assuage the participants' concerns about the potential for process to not reach acceptable final prices so that economic exchange would occur.

Taken together, the research articles that we have presented in this special issue offer a useful perspective on the development and extension of theory to understand some of the interesting technology adoption contexts of our time. The new application of the theory of consumer values by Hedman and Gimpel offers a wide spectrum of opportunity for the study of many different kinds of technology adoption phenomena, especially where the research analyst believes that adoption may come from hedonic rather than purely utilitarian uses. Also, it is likely that as the novelty of use of a new technology wears off-as is surely the case with the adoption of hyped technologies, it will be necessary to provide other secondary explanations of how the momentum of technology adoption really works. One of the guest editors, for example, had an experience-circa 1998 - with the adoption of an early hand-held "pocket PC" in the Hewlett-Packard Jornada series, with its tiny screen, Microsoft Pocket PC operating system and little connectivity with many of the other desktop applications of the time. It was clear: once the hype wears off, users need to have other motivations for using a device, lest no use will be observed at all. More recent hand-held devices, including the Blackberry and iPhone cell phones, the iPod and iTouch, and the Wii and xBox series for digital gaming and graphics have been enormously successful, in spite of their hype. They have done very well in their followthrough to satisfy a generation of consumers with the innovations that they have offered.

Another interesting thread in the special issue articles that we accepted is their use of behavioral theories at the level of individual technology adoption that offer rich interpretations that are different from how the theory of technology acceptance approaches these problems. For example, the work of Bermúdez-Edo, Hurtado-Torres and Aragon-Correa informs us about Web-based recruiting, and explicitly targets a blend of intrinsic and extrinsic explanations that go beyond the typical aspects of ease of use and usefulness to craft a more interesting and fuller perspective of what it takes for firms to succeed with recruiting efforts through their corporate Web sites. Similarly, the psychological and financial risks, and trust considerations that are explored by Kauffman, Lai and Lin in the online group-buying auction context point to a range of rich considerations. They make the case that it is important to gain a fuller understanding of many different kinds of mechanism designs in which the aggregation benefits of the technology platform develop in a manner that benefits market participants, when it can be guided by an auction initiator. 
Our work on the development of special issues on the topic of new theories, methods and applications in the area of technology adoption and diffusion for Information Technology and Management is continuing. We have a number of other articles that are still in the process of development as of the date that this special issue went to press. The main thrust of our approach in the review process, developmental reviewing, has been to take submissions with interesting ideas and shape them so that they offer stronger and more important contributions of new knowledge. We have tried to be patient with the development of the works, and not to try to rush any research article to publication that seems like it still will benefit from additional work and efforts to innovate and further enrich the ideas on the authors' part.

We would like to thank Varghese Jacob for his encouragement and support of this special issue, and for permitting us to adopt this developmental reviewing approach. It's always an honor to offer service this way to the research community and to work to help authors with the creation of high quality published research.
Deepika Jothinathan, the Information Technology and Management Journal Manager at Springer, made our work more productive. She offered able assistance with the processing of manuscripts on the reviewing system. She handled all the odd items swiftly that otherwise would have bogged us down and forced authors to wait longer than they might have liked to hear back from us. We are grateful to the reviewers who contributed their free time and effort to support the development of the special issue research for publication. We appreciated the responsiveness of the authors to the many different suggestions and input they received on their initial submissions, and their cooperation to arrive at a shared vision for what constituted a meaningful contribution of new knowledge and high quality scholarship. Finally, on behalf of the editors and the editorial board of Information Technology and Management, we would like to encourage other authors to explore the opportunity to publish new work on technology adoption and technological innovation in this journal. 